\title{
PReS-FINAL-2238: PAPA (pyogenic arthritis, pyoderma gangrenosum and acne) syndrome: results from the Eurofever registry
}

\author{
R Caorsi ${ }^{*}$, A Insalaco ${ }^{2}$, D Marotto $^{3}$, J Frenkel $^{4}$, A Martini $^{1}$, F De benedetti ${ }^{2}$, M Gattorno ${ }^{1}$, \\ The Paediatric Rheumatology International Trial Organization (PRINTO) and the Eurofever Project
}

From 20th Pediatric Rheumatology European Society (PReS) Congress

Ljubljana, Slovenia. 25-29 September 2013

\section{Introduction}

PAPA syndrome is a very rare autoinflammatory condition. Few data are nowadays available about the clinical characteristic, the response to treatment and the outcome of this disease.

\section{Objectives}

to analyse the data of the PAPA patients enrolled to the Eurofever registry.

\section{Methods}

The data analysed in the study were extracted from the Eurofever registry, which is hosted in the PRINTO website http://www.printo.it. The patients were included in the study in the presence of clinical manifestations consistent with PAPA syndrome and mutations in the PSTPIP1 gene. Demographic data, clinical manifestations and response to treatment were analysed.

\section{Results}

In February 2013 baseline and clinical information were available of 2567 patients from 88 centers in the Eurofever registry. Of these 16 patients PAPA patients (M:F = $8: 8)$, from 3 different centers, fulfilled the inclusion criteria and were therefore analysed: 10 were of the same family, in 3 patients the disease was caused by a de novo mutation while in 3 cases the mutation was found in one parent (not yet included in the registry). The mean age at enrolment was 26,22 years (4 paediatric and 12 adult patients). The mean age at disease onset was 5,7 years

${ }^{1}$ 2nd Division Of Pediatrics, Istituto Gaslini, Genoa, Italy

Full list of author information is available at the end of the article (range birth - 18 years). The mean age at diagnosis was 24,5 years (range 1,8 - 57,5), with a mean delay of 18,8 years (range 2 months - 50 years). The mutations found in the PSTPIP1 gene were V344I (1pt), E250K (1 pt), E257G (1 pt), A230T (2 pts), and E250Q (11 pts).

The disease course was recurrent in 8 patients, while the other 8 presented a chronic disease course with periodic recrudesces. 15 patients presented an articular involvement during their disease course, while 11 patients presented clinical manifestations affecting the skin (folliculitis in 8, pyoderma gangrenosum in 3, skin abscess 8 patients); five and one patients presented only the articular and skin involvement respectively. 2 patients complained with suppurative hidradenitis while 7 out of the 16 patients presented clinical manifestations not typical of PAPA syndrome (psoriasis, osteolytic bone lesions, chronic renal failure, muscular abscesses, anaemia and hepatosplenomegaly). 10 patients were treated with NSAID with poor response while steroids caused a complete or partial control of disease manifestations in 5 and 6 patients respectively. Two patients were treated with methotrexate with partial response. Etanercept was used in one patient with complete response, adalimumab in 3 patients ( 2 partial and 1 complete responders) and anakinra in 5 patients ( 2 partial and 3 complete responders).

\section{Conclusion}

The study analyses the largest series of PAPA syndrome patients described so far. The wide clinical heterogeneity and the usual presentation with a single manifestation might be responsible for under-recognition of the syndrome. 


\section{Disclosure of interest}

None declared.

\section{Authors' details}

${ }^{1}$ 2nd Division Of Pediatrics, Istituto Gaslini, Genoa, Italy. ${ }^{2}$ Department of Paediatrics, Ospedale Pediatrico Bambin Gesù, Rome, Italy. ${ }^{3}$ Department of Rheumatology, Tempio Pausania Hospital, Tempio Pausania (OT), Italy.

${ }^{4}$ Department of Paediatrics, University Medical Center, Utrecht, Netherlands.

Published: 5 December 2013

doi:10.1186/1546-0096-11-S2-P228

Cite this article as: Caorsi et al:: PReS-FINAL-2238: PAPA (pyogenic

arthritis, pyoderma gangrenosum and acne) syndrome: results from the Eurofever registry. Pediatric Rheumatology 2013 11(Suppl 2):P228.

Submit your next manuscript to BioMed Central and take full advantage of:

- Convenient online submission

- Thorough peer review

- No space constraints or color figure charges

- Immediate publication on acceptance

- Inclusion in PubMed, CAS, Scopus and Google Scholar

- Research which is freely available for redistribution

Submit your manuscript at www.biomedcentral.com/submit
Ciomed Central 